\title{
Analysis of the impact of selected socio-demographic factors on quality of life of asthma patients
}

\author{
Ewa Szynkiewicz ${ }^{1,2}$, Małgorzata Filanowicz², Małgorzata Graczyk¹, Bernadeta Cegła², Renata Jabłońska³, \\ Katarzyna Napiórkowska-Baran ${ }^{1}$, Zbigniew Bartuzi ${ }^{1}$
}

\author{
${ }^{1}$ Chair and Clinic of Allergology, Clinical Immunology and Internal Diseases, University Hospital No. 2, Bydgoszcz, Poland \\ Head: Prof. Zbigniew Bartuzi MD, PhD \\ 2Department of Nursing in Internal Diseases, Collegium Medicum, Nicolaus Copernicus University, Bydgoszcz, Poland \\ Head: Bernadeta Cegła PhD \\ ${ }^{3}$ Department of Neurological and Neurosurgical Nursing, Collegium Medicum, Nicolaus Copernicus University, Bydgoszcz, Poland \\ Head: Robert Ślusarz PhD
}

\begin{abstract}
Aim: To evaluate the influence of selected socio-demographic factors on quality of life of patients with different degrees of asthma severity.

Material and methods: The study was conducted in 2009-2010 in the Clinic of Allergology, Clinical Immunology and Internal Diseases in Dr J. Biziel University Hospital No. 2 in Bydgoszcz. Patients were divided into a tested group (126) and a control group (86). The criterion for the division was the degree of asthma control according to GINA 2006. The following tools were used: the author's questionnaire containing questions about socio-demographic and clinical data, and the WHOQOL-100.

Results: In the tested group, a statistically significant correlation was observed between quality of life and age ( $p<0.002$ for the entire population), education ( $p<0.05$ in the group with controlled asthma, $p=0.0005$ for the entire population), professional activity ( $p<0.003$ in the group with partially controlled asthma, $p<0.05$ with uncontrolled asthma and $p<0.0001$ in the entire population), marital status ( $p=0.025$ for the entire population) and financial situation ( $p<0.0001 ; p<0.0002 ; p<0.009$ in all groups; $p<0.0001$ in the entire population). There was no significant difference between quality of life, and sex and the place of residence of the respondents.

Conclusions: Age, education, professional activity, marital status and financial situation affect the assessment of quality of life in patients with asthma. Socio-demographic factors such as sex and the place of residence do not influence the assessment of quality of life in patients with asthma.
\end{abstract}

Key words: socio-demographic factors, quality of life, asthma, degree of control.

\section{Introduction}

The issue of quality of life has become one of the most important concepts in medicine in recent years. Being analyzed in many areas of life, it results in a change in the perception of patients. It complements the assessment of patients' health status and allows planning and organizing comprehensive care. It also contributes to patient subjectivity and leads to improving the quality of life in all spheres of human functioning. Identification and treatment of disorders connected with health-related quality of life is considered to be one of the important elements of con- temporary conduct in various forms of pathology [1-4]. The literature mentions asthma as a clinical entity and the importance of the research on quality of life in patients with asthma. Unfortunately, few of such reports concern the impact of socio-demographic factors on quality of life in patients with different degrees of asthma severity.

\section{Aim}

The aim of this study was to evaluate the influence of selected socio-demographic factors on quality of life of patients with different degrees of asthma severity. The fol-

Address for correspondence: Ewa Szynkiewicz MD, PhD, Chair and Clinic of Allergology, Clinical Immunology and Internal Diseases, University Hospital No. 2, 75 Ujejskiego St, 85-168 Bydgoszcz, Poland, phone: +48 502358 797, +48 523655551 , fax: +48 523484076 , e-mail: ewaszynkiewicz@wp.pl

Received: 5.03.2013, accepted: 23.06.2013. 
lowing factors were evaluated: age, sex, education, professional activity, marital status, place of residence and financial situation.

\section{Material and methods}

Patients who were hospitalized in the Clinic of Allergology, Clinical Immunology and Internal Diseases, and treated in the Outpatient Clinic were qualified for the study. They also: were diagnosed with bronchial asthma by an allergist, gave written informed consent to participate in the study.

On this basis, 252 patients were included in the study and subjected to the first evaluation. In the next phase of the study, 40 patients were excluded. The exclusion criteria were as follows:

- age under 18 years and over 65 years,

- pregnancy or diagnosis of chronic obstructive pulmonary disease,

- chronic severe organ or systemic diseases (e.g. systemic lupus erythematosus, cancer, renal failure, epilepsy, Parkinson's disease, rheumatoid arthritis, circulatory failure, multiple sclerosis),

- other health conditions that prevent conscious and unassisted completion of the survey questionnaires.

The study began in 2009 and was completed in early October 2010. The respondents were always informed about the purpose and the subject of the research. They had an opportunity to ask questions and withdraw from the study in every of its stages without any consequences. The way of conducting the study ensured freedom of expression and respect for personal dignity while asking the questions. All patients signed the consent to participate in the research. The permission to carry out the research was granted by the Bioethics Committee of Collegium Medicum in Bydgoszcz at the Nicolaus Copernicus University (KB/513/2008).

The study included 212 patients with 144 women and 68 men aged 18-64. The average age of the examined group was $44.9 \pm 12.5$ years, including women aged $43.7 \pm 12.5$ years and men aged $47.4 \pm 12.3$ years. The patients were divided into a tested and a control group. The criterion for the division was the degree of asthma control according to the Global Initiative for Asthma 2006 (GINA), evaluated by a doctor, based on the medical examination and analysis of medical records. The tested group comprised patients diagnosed with uncontrolled and partially controlled asthma. The control group consisted of patients with controlled asthma. The study was conducted using a diagnostic survey with an interview technique.

The study was carried out by means of the following questionnaires:

-WHOQOL-100 (World Health Organization Quality of Life) in the Polish version, which examines quality of life and consists of 100 questions divided into 24 subscales falling under the six areas of life: physical, psychological, independence, social, environmental and spiritual. Addi- tionally, it contains a general subscale, which consists of 4 questions concerning global assessment of quality of life and general health status $[5,6]$;

- the author's questionnaire containing questions about socio-demographic and clinical data.

The results obtained from asthma patients were statistically analyzed in order to assess quality of life in the compared groups, and to identify any correlations between quality of life and the selected parameters. It has been shown that the distribution of quality of life in the tested groups does not differ significantly from normal ones, which made it possible to use parametric tests to compare the mean values.

\section{Statistical analysis}

The following methods and statistical tests were used in the study.

1. Parametric Z-test comparing mean values in two sufficiently large size $(\geq 50)$ groups.

2. Snedecor's and Levene's parametric F-tests to verify the hypothesis of homogeneity of variances in two compared groups. The choice of an appropriate test to compare the means depends on the results of testing.

3. Parametric tests to compare the mean values in the two groups. In the cases of homogeneity of variances in the two groups, the Student's t-test was used to verify the hypothesis of the equality of the means. When this condition was not met (the variances turned out to be different), the modified test of Cochran and Cox was used. 4. The one-way analysis of variance ANOVA to verify the hypothesis about the equality of means in more than two groups, assuming a normal distribution and uniformity of variances.

5. The least significant difference test (LSD test) from the post-hoc group, evaluating the difference between the mean values in several groups.

6. Pearson's correlation coefficient calculated and verified for significance by means of the Student's t-test.

The significance level $p=0.05$, for which critical values had been given, was accepted as reliable when verifying the hypotheses. The $p$-values were also given. These are the probabilities with which a mistake can be made by rejecting the hypothesis being checked and noting that differences in the compared populations are significant. At $p<0.05$, a difference is considered statistically significant. The statistical analysis of the results was conducted by means of the software package "Statistica" v.9.0.

\section{Results}

The first determinant submitted for the analysis and study of correlation was age. In order to determine the correlation between quality of life and age, the Pearson correlation coefficients were calculated and verified for the significance. The results of calculations are shown in Table 1. 
Table 1. Relationship between quality of life and age

\begin{tabular}{cccccc}
\hline Age and quality of life & \multicolumn{3}{c}{ Degrees of asthma control } & \multirow{2}{*}{ All } \\
\cline { 2 - 5 } & & Controlled & Partially controlled & Uncontrolled & \\
\hline$n$ & 86 & 50 & 76 & 212 \\
\hline Correlation coefficient & $R_{x y}$ & -0.01 & -0.25 & -0.16 & -0.21 \\
\hline Student's $t$-test & $t_{c r}$ & 1.99 & 2.01 & 1.99 & 1.97 \\
\cline { 2 - 5 } & $t$ & 0.09 & 1.75 & 1.47 & 3.27 \\
\cline { 2 - 5 } & 0.93 & 0.09 & 0.15 & $<0.002$ \\
\hline
\end{tabular}

Table 2. Quality of life and sex

\begin{tabular}{|c|c|c|c|c|c|c|c|c|c|}
\hline \multirow{3}{*}{$\begin{array}{l}\text { Sex and quality } \\
\text { of life }\end{array}$} & \multicolumn{7}{|c|}{ Degrees of astma control } & \multirow{2}{*}{\multicolumn{2}{|c|}{ All }} \\
\hline & & \multicolumn{2}{|r|}{ Controlled } & \multicolumn{2}{|c|}{ Partially controlled } & \multicolumn{2}{|c|}{ Uncontrolled } & & \\
\hline & & $n$ & Mean \pm SD & $n$ & Mean \pm SD & $n$ & Mean \pm SD & $n$ & Mean \pm SD \\
\hline Women & & 66 & $0.624 \pm 0.109$ & 36 & $0.600 \pm 0.114$ & 42 & $0.567 \pm 0.091$ & 144 & $0.598 \pm 0.113$ \\
\hline Men & & 20 & $0.638 \pm 0.101$ & 14 & $0.549 \pm 0.100$ & 34 & $0.684 \pm 0.133$ & 68 & $0.593 \pm 0.098$ \\
\hline \multirow[t]{2}{*}{ Snedecor's F-test } & $F$ & & $F=1.18<1.98=F_{c r}$ & \multicolumn{2}{|c|}{$F=1.28<2.36=F_{c r}$} & \multicolumn{2}{|c|}{$F=1.44<1.76=F_{c r}$} & & - \\
\hline & $p$ & & 0.36 & & 0.33 & & 0.14 & & - \\
\hline \multirow[t]{2}{*}{ Student's $t$-test } & $t$ & & $t=0.52<1.99=t_{c r}$ & \multicolumn{2}{|c|}{$t=1.45<2.01=t_{c r}$} & \multicolumn{2}{|c|}{$t=1.34<1.99=t_{c r}$} & & $z=0.27$ \\
\hline & $p$ & & 0.61 & & 0.15 & & 0.18 & & 0.78 \\
\hline
\end{tabular}

Table 3. Quality of life and education

\begin{tabular}{|c|c|c|c|c|c|c|c|c|c|}
\hline \multirow{3}{*}{\multicolumn{2}{|c|}{$\begin{array}{l}\text { Education and } \\
\text { quality of life }\end{array}$}} & \multicolumn{6}{|c|}{ Degrees of asthma control } & \multirow{2}{*}{\multicolumn{2}{|c|}{ All }} \\
\hline & & \multicolumn{2}{|c|}{ Controlled } & \multicolumn{2}{|c|}{ Partially controlled } & \multicolumn{2}{|c|}{ Uncontrolled } & & \\
\hline & & $n$ & Mean \pm SD & $n$ & Mean \pm SD & $n$ & Mean \pm SD & $n$ & Mean \pm SD \\
\hline Primary and vocationa & & 19 & $0.578 \pm 0.108$ & 19 & $0.560 \pm 0.099$ & 34 & $0.567 \pm 0.091$ & 72 & $0.568 \pm 0.097$ \\
\hline Secondary & & 33 & $0.630 \pm 0.103$ & 21 & $0.599 \pm 0.087$ & 38 & $0.558 \pm 0.100$ & 92 & $0.593 \pm 0.103$ \\
\hline Higher & & 34 & $0.652 \pm 0.105$ & 10 & $0.605 \pm 0.107$ & 4 & $0.684 \pm 0.133$ & 48 & $0.645 \pm 0.122$ \\
\hline \multirow[t]{2}{*}{ ANOVA test } & $F$ & \multicolumn{2}{|c|}{$F=3.11>3.06=F_{c r}$} & \multicolumn{2}{|c|}{$F=0.80<3.19=F_{c r}$} & \multicolumn{2}{|c|}{$F=3.04<3.12=F_{c r}$} & \multicolumn{2}{|c|}{$F=7.80>3.04=F_{c}$} \\
\hline & $p$ & & $<0.05$ & & 0.46 & & 0.054 & & 0.0005 \\
\hline
\end{tabular}

In all groups, the calculated coefficients are negative, which indicates that along with age, the quality of life slightly but usually decreases. The significance of correlation was only found for the entire tested population. Another analyzed factor whose relationship with QOL in patients with asthma was examined was sex. The parametric Student's t-test, and z-test based on the normal distribution (the latter one in order to compare the average levels of quality of life in the whole population) were used. There was no significant difference between the quality of life for men and women - calculated values are higher than critical values $(p>0.05)$. The results are shown in Table 2 .
Table 3 shows the results concerning QOL and its relationship with patient education. In all groups and in the entire population, the level of quality of life increases along with the level of education. A significant increase was shown in the group with controlled asthma, and in the whole population - the average assessment of quality of life is significantly higher in the subgroups with higher education compared with a subgroup with primary and vocational education.

Another group of data that was subjected to a statistical analysis concerned the place of residence of the patients. It was examined whether living in the country- 
Table 4. Quality of life and the place of residence

\begin{tabular}{|c|c|c|c|c|c|c|c|c|c|}
\hline \multirow{3}{*}{$\begin{array}{l}\text { Place of residence } \\
\text { and quality of life }\end{array}$} & & \multicolumn{6}{|c|}{ Degrees of asthma control } & \multirow{2}{*}{\multicolumn{2}{|c|}{ All }} \\
\hline & & \multicolumn{2}{|r|}{ Controlled } & \multicolumn{2}{|c|}{ Partially controlled } & \multicolumn{2}{|c|}{ Uncontrolled } & & \\
\hline & & $n$ & Mean \pm SD & $n$ & Mean \pm SD & $n$ & Mean \pm SD & $n$ & Mean \pm SD \\
\hline City & & 65 & $0.637 \pm 0.102$ & 40 & $0.594 \pm 0.109$ & 53 & $0.555 \pm 0.099$ & 158 & $0.599 \pm 0.109$ \\
\hline Village & & 21 & $0.596 \pm 0.116$ & 10 & $0.550 \pm 0.108$ & 23 & $0.600 \pm 0.097$ & 54 & $0.589 \pm 0.107$ \\
\hline \multirow[t]{2}{*}{ Snedecor's F-test } & $F$ & & $\mathrm{~F}=1.27<1.74=F_{c r}$ & & $\mathrm{~F}=1.06<2.13=F_{c r}$ & & $=1.01<1.75=F_{c r}$ & & - \\
\hline & $p$ & & 0.23 & & 0.41 & & 0.47 & & - \\
\hline \multirow[t]{2}{*}{ Student's $t$-test } & $t$ & & $t=1.56<1.99=t_{c r}$ & & $t=1.13<2.01=t_{c r}$ & & $=1.81<1.99=t_{c r}$ & & $z=0.58$ \\
\hline & $p$ & & 0.12 & & 0.27 & & 0.07 & & 0.56 \\
\hline
\end{tabular}

Table 5. Quality of life and professional activity

\begin{tabular}{|c|c|c|c|c|c|c|c|c|c|}
\hline \multirow{3}{*}{$\begin{array}{l}\text { Profesional activity } \\
\text { and quality of life }\end{array}$} & & \multicolumn{6}{|c|}{ Degrees of asthma control } & \multirow{2}{*}{\multicolumn{2}{|c|}{ All }} \\
\hline & & \multicolumn{2}{|c|}{ Controlled } & \multicolumn{2}{|c|}{ Partially controlled } & \multicolumn{2}{|c|}{ Uncontrolled } & & \\
\hline & & $n$ & Mean \pm SD & $n$ & Mean \pm SD & $n$ & Mean \pm SD & $n$ & Mean \pm SD \\
\hline Does not work & & 21 & $0.597 \pm 0.113$ & 31 & $0.559 \pm 0.107$ & 43 & $0.548 \pm 0.085$ & 95 & $0.562 \pm 0.100$ \\
\hline Works & & 64 & $0.637 \pm 0.105$ & 19 & $0.630 \pm 0.102$ & 32 & $0.596 \pm 0.114$ & 115 & $0.624 \pm 0.108$ \\
\hline \multirow[t]{2}{*}{ Snedecor's F-test } & $F$ & \multicolumn{2}{|c|}{$F=1.16<1.74=F_{c r}$} & \multicolumn{2}{|c|}{$F=1.07<2.11=F_{c r}$} & \multicolumn{2}{|c|}{$F=1.80>1.72=F_{c r}$} & & - \\
\hline & $p$ & & 0.32 & & 0.45 & & 0.04 & & - \\
\hline \multirow{2}{*}{$\begin{array}{l}T \text {-Student's test and } \\
\text { Cochran-Cox's test }\end{array}$} & $t$ & \multicolumn{2}{|c|}{$t=1.49<1.99=t_{c r}$} & \multicolumn{2}{|c|}{$t=2.28>2.01=t_{c r}$} & \multicolumn{2}{|c|}{$C=2.10>2.03=C_{c r}$} & & $z=4.32$ \\
\hline & $p$ & & 0.14 & & $<0.003$ & & $<0.05$ & & $<0.0001$ \\
\hline
\end{tabular}

Table 6. Quality of life and marital status

\begin{tabular}{|c|c|c|c|c|c|c|c|c|c|}
\hline \multirow{3}{*}{\multicolumn{2}{|c|}{$\begin{array}{l}\text { Material status } \\
\text { and quality of life }\end{array}$}} & \multicolumn{6}{|c|}{ Degrees of asthma control } & \multirow{2}{*}{\multicolumn{2}{|c|}{ All }} \\
\hline & & \multicolumn{2}{|c|}{ Controlled } & \multicolumn{2}{|c|}{ Partially controlled } & \multicolumn{2}{|c|}{ Uncontrolled } & & \\
\hline & & $n$ & Mean \pm SD & $n$ & Mean \pm SD & $n$ & Mean \pm SD & $n$ & Mean \pm SD \\
\hline Single & & 33 & $0.645 \pm 0.100$ & 19 & $0.620 \pm 0.124$ & 13 & $0.570 \pm 0.146$ & 65 & $0.623 \pm 0.118$ \\
\hline Married & & 53 & $0.616 \pm 0.111$ & 31 & $0.565 \pm 0.100$ & 63 & $0.568 \pm 0.090$ & 147 & $0.585 \pm 0.102$ \\
\hline \multirow[t]{2}{*}{ Snedecor's F-test } & $F$ & \multicolumn{2}{|c|}{$F=1.23<1.73=F_{c r}$} & \multicolumn{2}{|c|}{$F=1.54<1.96=F_{c r}$} & \multicolumn{2}{|c|}{$F=2.67>1.91=F_{c r}$} & & - \\
\hline & $p$ & & 0.27 & & 0.15 & & 0.006 & & - \\
\hline \multirow{2}{*}{$\begin{array}{l}T \text {-Student's test } \\
\text { and Cochran-Cox's test }\end{array}$} & $t$ & \multicolumn{2}{|c|}{$t=1.25<1.99=t_{c r}$} & \multicolumn{2}{|c|}{$t=1.72<2.01=t_{c r}$} & \multicolumn{2}{|c|}{$C=0.04<2.17=C_{c r}$} & & $z=2.24$ \\
\hline & $p$ & & 0.22 & & 0.09 & & 0.95 & & 0.025 \\
\hline
\end{tabular}

side or in the city has an impact on quality of life. The parametric Student's t-test and z-test based on the normal distribution (the latter one in order to compare the average levels of quality of life in the whole population) were used. There was no significant difference between the quality of life of the inhabitants of cities and villages - calculat- ed values are lower than the critical values $(p>0.05)$. The results are shown in Table 4.

The results concerning professional activity of patients were also statistically analysed. Professional life is an important factor which may affect quality of life. The parametric Student's t test, Cochran-Cox test and z-test based on 
Table 7. Quality of life and financial situation

\begin{tabular}{|c|c|c|c|c|c|c|c|c|c|}
\hline \multirow{3}{*}{$\begin{array}{l}\text { Financial situation } \\
\text { and quality of life }\end{array}$} & & \multicolumn{6}{|c|}{ Degrees of asthma control } & \multirow{2}{*}{\multicolumn{2}{|c|}{ All }} \\
\hline & & \multicolumn{2}{|c|}{ Controlled } & \multicolumn{2}{|c|}{ Partially controlled } & \multicolumn{2}{|c|}{ Uncontrolled } & & \\
\hline & & $n$ & Mean \pm SD & $n$ & Mean \pm SD & $n$ & Mean \pm SD & $n$ & Mean \pm SD \\
\hline Good & & 74 & $0.644 \pm 0.094$ & 41 & $0.612 \pm 0.096$ & 63 & $0.581 \pm 0.095$ & 178 & $0.614 \pm 0.098$ \\
\hline Bad & & 11 & $0.496 \pm 0.093$ & 8 & $0.460 \pm 0.105$ & 12 & $0.500 \pm 0.108$ & 31 & $0.488 \pm 0.100$ \\
\hline \multirow[t]{2}{*}{ Snedecor's F-test } & $F$ & \multicolumn{2}{|c|}{$F=1.01<2.61=F_{c r}$} & \multicolumn{2}{|c|}{$F=1.20<2.25=F_{c r}$} & \multicolumn{2}{|c|}{$F=1.28<1.95=F_{c r}$} & \multicolumn{2}{|c|}{$F=1.04<1.52=F_{c r}$} \\
\hline & $p$ & & 0.54 & & 0.32 & & 0.26 & & 0.42 \\
\hline \multirow[t]{2}{*}{ Student's $t$-test } & $t$ & \multicolumn{2}{|c|}{$t=4.89>1.99=t_{c r}$} & \multicolumn{2}{|c|}{$t=4.03>2.01=t_{c r}$} & \multicolumn{2}{|c|}{$t=2.67>1.99=t_{c r}$} & \multicolumn{2}{|c|}{$t=6.55>1.97=t_{c r}$} \\
\hline & $p$ & & $<0.0001$ & & 0.0002 & & 0.009 & & $<0.0001$ \\
\hline
\end{tabular}

the normal distribution (the latter one in order to compare the average levels of quality of life in the whole population) were used. In all cases, the levels of quality of life are numerically higher for the employed people. A significant difference was observed in three cases: in the groups with partially controlled and uncontrolled asthma and in the entire population. The results of the calculations and the analysis of this issue are presented in Table 5.

Another determinant of quality of life subjected to an examination and assessment was marital status. In all cases, the average levels of quality of life of singles are higher than these of married people. A significant difference was observed only in the entire population. The results of the statistical analysis are shown in Table 6.

One of the important elements affecting a person's life is financial situation. It was also taken into account while examining the relationship between quality of life and sociodemographic factors. The data presented in Table 7 show that in all groups and in the entire population, the average level of quality of life is significantly higher in patients whose financial situation is rated as good.

\section{Discussion}

Studies of quality of life in asthma are a valuable source of information about patients. They provide a large number of data on various areas and aspects of patient's life. They identify threats, allow to choose an appropriate way of therapy and individualize the treatment process. They are determinants of planning and implementing holistic care for particular patients or groups of patients. The studies also indicate changes taking place over time and differentiate patients, giving an opportunity to predict the consequences of the disease in the future. Hence, it becomes reasonable to indicate socio-demographic factors relevant to the assessment of quality of life of patients.

The age of patients in the author's own material ranged from 18 to 65 years and is comparable to the materials by Lewandowska et al. [7] (the youngest subject was 19, the oldest -75 years old), Schatz et al. [8] (the youngest -18 , the oldest - 54), Chełmińska et al. [9] (the youngest - 18, the oldest -40), Pietras et al. [10, 11] (the youngest - 22, the oldest -80), Uchmanowicz et al. [12] (the criterion for inclusion in the study - age over 18 years) [13].The average age in the author's study $(44.9 \pm 12.5)$ is comparable with the results of other authors [10, 14-17], in other publications, the average was 30 years [9, 18], or 36 [19].

Older people, more than any other age groups, suffer deficiencies in satisfying their needs. They often have a bad financial situation. Over the years, health status and overall performance deteriorates, which affects their life situation and social position. According to Szatur-Jaworska [20], lifespan has the greatest impact on psychological wellbeing of Poles. A mental condition, which is connected with the social situation, deteriorates with age. Also a physical condition gradually gets worse with age. Slavin indicates that age is an important factor that affects the anatomy and physiology of lungs [21].

The World Health Organization regards the age of 60 as the beginning of old age while the United Nations -65 . In Poland, the beginning of old age is associated with retirement (60 years for women and 65 for men) [22]. According to Lindner et al. [23], asthma is a common disease in the elderly people, and its symptoms are less specific or altered by co-morbidities. Presentation of the disease is not typical and is often unrecognized [24-27]. Kowalski et al. [18] in their research indicate the average occurrence of asthma symptoms being four times a week. Greater frequency was seen among adults aged 55-64 years. In the studies conducted by Uchmanowicz et al. [15] in 2008-2009 in Wroclaw, selected socio-demographic characteristics (age, sex, education) were evaluated as well as their impact on the quality of life of patients with asthma using the general questionnaire EuroQol (EQ-5D) and the disease-specific Asthma Quality of Life Questionnaire (AQLQ). It was observed that with age, the assessment of quality of life is lower in more than one domain (environmental stimuli, activity limitations). Deterioration in quality of life in all areas occurred in people over 50 years of age. Other authors confirm these data $[28,29]$. 
In our own study, the level of quality of life decreased with age. Significance of the correlation was only found for the entire study population $(p<0.002)$.

Taking into consideration sex, 144 women (67.9\%) and 68 men (32.1\%) were examined. In the study by Schatz et al. [8], the percentage of women was $68 \%$, in Uchmanowicz et al. [15] - 72\%, in Laforest et al. [19] - 62\%, in Chełmińska et al. [30] - 66\%, in Ferreira et al. [16] - 70\% and in Kowalski et al. [18] - 63\%. Epidemiological studies conducted by Melgert et al. [31] show that women are at increased risk of developing asthma in early adulthood. They suffer from the disease more often than men. It seems that these differences are caused by biological differences between two sexes (genetic, pulmonary, immunological causes) as well as socio-cultural and environmental dissimilarities [32]. The researchers highlight the role of sex hormones as the main determinants of risk of the disease in adolescence [33, 34]. Differences in the frequency and expression of asthma depending on sex, according to Sozańska et al. [30] indicate a male predominance before puberty $(2: 1)$ and female during puberty $(3: 1)$. The research by Kowalski et al. [18] shows the average more frequent occurrence of asthma symptoms in women.

The results of the present study do not show differences in quality of life in relation to sex $(p=0.78)$, which is consistent with the results obtained by other authors [15, 35], but some [19, 32, 36-41] observed a lower level of quality of life in women and more frequent use of medical care compared to men, despite receiving similar treatment.

In the further stage of the research, an attempt was made to determine the extent to which education affects the assessment of quality of life. The results of the study show that in all groups and in the entire population, the level of quality of life increases with the level of education. A significant increase was observed in the control group $(p<0.05)$ and in the whole population $(p<0.0005)$.

There is a consensus among researchers on the impact of education on quality of life in patients with bronchial asthma. Previously cited studies by Uchmanowicz et al. [15] showed a statistically significant correlation between education and the following domains concerning the symptoms: activity limitations and environmental stimuli. Selfesteem is lower in people with vocational education than in those with a higher level of education. Also, Chen et al. [42], using in their research the questionnaires AQLQ and EQ-5D, have proved that a low level of education results in a lower quality of life in patients with bronchial asthma. A similar view is shared by Ferreira et al. [16], indicating that quality of life is better in patients with higher education and higher income. This is confirmed by the research conducted by Blozik et al. [43], in which greater limitations of quality of life were associated with lower education.

Another type of analyzed data concerned the place of residence. The study showed no significant difference between the quality of life of inhabitants of towns and villages $(p>0.05)$. This is confirmed by the studies conducted by Hans-Wytrychowska et al. [44] on a population of 275 patients with asthma using the SGRQ. This may prove that in modern times, rural population is not only agricultural population. The studies by Yen et al. [45] which assessed the impact of the place of residence on an adult population with asthma in northern California are interesting on this background. The relationship between quality of life, physical functioning and depressive symptoms and various problems in the surrounding environment (traffic, noise, pollution, smell, fires) was evaluated by 435 respondents. A higher level of perceived difficulties in the area was associated with a lower quality of life, worse physical functioning and an increase in depressive symptoms. Previously brought up studies by Ferreira et al. [16] also point out to a link between quality of life and the place of residence, indicating a higher assessment of quality of life by people from urban areas.

Some studies have reported that professional activity $[16,19]$ leads to a higher assessment of quality of life, while other studies have not supported this relationship [44]. Inability to perform work due to the limitations caused by an illness may result in lower self-esteem and socioeconomic status.

In our study, there was a statistically significant correlation between professional activity and perception of quality of life. The difference was found in three cases in the group with partially controlled $(p<0.003)$ and uncontrolled asthma $(p<0.05)$ and in the whole population $(p<0.0001)$. Self-assessment of quality of life of employed people is higher than of those who do not work (unemployed, pensioners).

The study by Archea et al. [46] showed the impact of negative and stressful events on the perception of quality of life, especially among patients with a lower socioeconomic status. Thus, the results obtained by Ferreira et al. [16], which showed that the amount of the average monthly net income determines the self-assessment of quality of life, will not be surprising. According to the author, higher income resulted in better perception of quality of life. Bandiera et al. [47], in a cross-sectional study conducted in 2004 in the United States, highlight the relationship between asthma, low income, minorities (racial and ethnic) and mental health. Similar studies were conducted by Wisnivesky et al. [48], assessing quality of life of patients with asthma from poor neighborhoods of New York. Sex and a low socioeconomic status were regarded as most important risk factors associated with the exacerbations of the disease and mortality rate. This is also confirmed by other authors [29].

In our research, a significantly higher level of perceived quality of life was observed in patients who better rated their financial situation (controlled asthma $p<0.0001$, partially controlled asthma $p<0.0002$, uncontrolled asthma $p<0.009$, entire population $p<0.0001$ ).

The literature mentions the impact of the socioeconomic factor which is the marital status on quality of life. 
In the research by Wang et al. [35], carried out in Taiwan by means of the questionnaire St. George's Respiratory Questionnaire (SGRQ) in the Chinese version, marital status had an impact on the perception of quality of life. Married patients received lower scores concerning quality of life. In the study by Ferreira et al. [16], single people and marriages presented higher quality of life than those who had got divorced and widowed people.

In our study, in all cases, the average levels of quality of life of single people were higher than those of married patients. A significant difference was only present in the entire population $(p=0.0025)$.

\section{Conclusions}

Chronic diseases lower well-being and cause negative emotions. Asthma is a condition that significantly affects quality of life, reducing in various ways activity levels in patients, physically, emotionally, and socially.

Quality of life in patients with asthma depends on many factors. In the conducted study, age, education, professional activity, marital status and financial condition can be included as the elements modifying QOL. There was no relationship between sex, place of residence and quality of life.

The degree of asthma control has important social and economic implications. Based on the conducted research, significant differences were noticed in the quality of life in patients with bronchial asthma according to the degree of the disease control. Adherence to GINA guidelines will reduce the severity of symptoms or exacerbations and will help patients avoid unnecessary hospitalizations.

\section{References}

1. Dziurowicz-Kozłowska A. Around the concept of quality of life. Psychology of quality of life [Polish]. Academica SWPS Warsaw 2002; 4: 77-100.

2. Papuć E. Quality of life - definitions and methods of its describing [Polish]. Curr Prob Psychiatry 2011; 12: 141-5.

3. Świnoga M, Kłos M, Miniszewska J, Zalewska-Janowska A. Health-related quality of life in dermatological and allergodermatological patients. Postep Derm Alergol 2012; 29: 69-73.

4. Bączyk G, Talarska D, Zawirska A, Adamski Z. Functioning and quality of life of patients with leg ulcers treated at dermatology wards. Postep Derm Alergol 2011; 28: 191-6.

5. Jaracz K, Wołowicka L, Kalfoss M. Validation analysis of the Polish version of WHOQOL-100 [Polish]. In: Quality of life in medical sciences. Wołowicka L (ed.). Wydawnictwo Uczelniane Akademii Medycznej im. Karola Marcinkowskiego w Poznaniu, Poznań 2001; 291-302.

6. Suliburska J, Bogdański P, Pupek-Musialik D, et al. Tobaccorelated Foetal Origin of Adult Diseases Hypothesis - population studies in Poland. Ann Agric Environ Med 2012; 19: $117-28$

7. Lewandowska K, Specjalski K, Jassem E, Słonimski JM. Style of coping with stress and emotional functioning in patients with asthma [Polish]. Pneumonol Alergol Pol 2009; 77: 31-6.

8. Schatz M, Clark S, Camargo CA. Sex differences in the presentation and course of asthma hospitalizations. Chest 2006; 129: 50-5.
9. Chełmińska M, Werachowska L, Niedoszytko M, et al. Quality of life of patients with well and badly-controlled asthma [Polish]. Pneumonol Alergol Pol 2007; 75: 70-5.

10. Pietras T, Panek M, Witusik A, et al. The analysis of relationships between anxiety, depression and exacerbation of dyspnea and severity of asthma [Polish]. Post Dermatol Alergol 2010; 27: 390-9.

11. Pietras T, Panek M, Wituski A, et al. Analysis of the correlation between level of anxiety, intensity of depression and bronchial asthma control. Postep Derm Alergol 2011; 28: 15-22.

12. Uchmanowicz I, Fal A M, Jankowska-Polasińska B. Does sex affect the results of quality of life in patients with asthma? [Polish]. Alergol Info 2011; 6: 46-51.

13. Zejda JE, Brożek GM, Farnik M, Smółka I. Social and familyrelated correlates of medical care utilization by asthmatic children in Upper Silesia, Poland. Ann Agric Environ Med 2012; 19: 141-5.

14. Santos A, Geraldes L, Sousa N, et al. Quality of life in asthma: comparison between severe and mild asthma. XXVII Congress of the European Academy of Alergology and Clinical Immunology. Postersession - Clinical Aspect of Asthma II. Barcelona 7-11 June 2008.

15. Uchmanowicz I, Jankowska B, Panaszek B, Fal AM. The influence of socio-demographic factors on quality of life of patients with asthma [Polish]. Alergol Info 2010; 5: 57-65.

16. Ferreira LN, Brito U, Ferreira PL. Quality of life in asthma patients. Rev Pol Pneumol 2010; 16: 23-55.

17. Schatz M, Mosen D, Apter A, et al. Relationship among quality of life, severity, and control measures in asthma: an evaluation using factor analysis. J Allergy Clin Immun 2005; 115: 1049-55.

18. Kowalski $M$, Jędrzejczak $M$, Cirlic $M$. The effectiveness of treatment of asthma in Poland in the evaluation of patients - the results of AIRCEE (Asthma Insights \& Reality in Central and Eastern Europe) [Polish]. Alerg Astma Immun 2004; 9: 187-95.

19. Laforest L, Pacheco Y, Bartsch P, et al. Correlates of quality of life in patients with asthma. Ann Allerg Asthma Im 2005; 94: 473-9.

20. Szatur-Jaworska B. Ouality of life in old age - an attempt to diagnose [Polish]. In: Social diagnosis 2005. J Czapiński, T Panek (ed.). Conditions and quality of life of Poles. Aspra-JR, Warsaw 2006; 1-11.

21. Slavin RG. Asthma in the elderly [Polish]. Aging Health 2005; 1: 435-40.

22. Szukalski P. Population ageing - the challenge of the twenty-first century [Polish]. In: Preparing for old age. The Poles in the face of ageing. Szukalski P (ed.). Instytut Spraw Publicznych, Warsaw 2009; 18-22

23. Lindner K, Panaszek B, Machaj Z. Diagnostic distinctions of bronchial asthma in the elderly [Polish]. Pneumonol Alergol Pol 2008; 76: 246-52.

24. Barua P, O' Mahony MS. Overcoming gaps in the management of asthma in older patients. New insights. Drugs Aging 2005; 22: 1029-59.

25. Radziwitł K, Kruszewski J. Evaluation of the size of the placebo effect in treatments of allergic diseases and asthma based on a meta-analysis of efficacy trials of drugs. Postep Derm Alergol 2011; 28: 372-7.

26. Pałgan K, Bartuzi Z. The role of flavonoids in asthma. Postep Derm Alergol 2011; 28: 396-401.

27. Oleś D, Szczepankiewicz A. Role of Toll-like receptors in the development of allergic inflammation in asthma. Postep Derm Alergol 2012; 29: 275-8. 
28. Ponte EV, Petroni J, Ramos DCB, et al. Perception of asthma control in asthma patients. J Bras Pneumol 2007; 33: 635-40.

29. Gunnells LC. Very poorly-controlled asthma among adults in Washington State. Wash State J Public Health Pract 2010; 3: 49-57.

30. Sozańska B, Nowak A, Boznański A. Sex and allergic diseases [Polish]. Alerg Astma Immun 2006; 11: 133-6.

31. Melgert BN, Ray A, Hylkema MN, et al. Are there reasons why adult asthma is more common in females? Curr Allergy Asthma Rep 2007; 7: 143-50.

32. Kynyk JA, Mastronarde JG, Mc Callister JW. Astma the sex difference. Curr Opin Pulm Med 2011; 17: 6-11.

33. Forbes L. Asthma and atopy: endocrine and metabolic conditions? Thorax 2005; 60: 793-4.

34. Balzano G, Fushillo S, Melillo G. Asthma and sex hormones. Allergy 2001; 56: 13-20.

35. Wang KY, Wu CP, Tang YY, Yang ML. Health-related quality of life in Taiwanese patients with bronchial asthma. J Formos Med Assoc 2004; 103: 205-211.

36. Skrzypulec V, Drosdzol A, Nowosielski K. The influence of bronchial asthma on the quality of life and sexual functioning of women. J Physiol Pharmacol 2007; 58: 647-55.

37. Naleway AL, Vollmer WM, Frazier EA, et al. Gender differences in asthma management and quality of life. J Asthma 2006; 43: 549-52.

38. Sundberg R, Palmqvist M, Tunsäter A, Torèn K. Health-related quality of life in young adults with asthma. Resp Med 2009; 103: 15-80.

39. Fal AM, Pawłowicz R. The parameters of assessment of asthma control [Polish]. Pediatria Med Rodz 2009; 5: 154-9.

40. Nowobilski R, De Barbaro B, Furgał M. The analysis of depression in people with asthma [Polish]. Alerg Astma Immun 2002; 7: 211-5.

41. Clark NM, Gong ZM, Wang SJ, et al. From the female perspective: long-term effects on quality of life of a program for women with asthma. Gend Med 2010; 7: 125-36.

42. Chen H, Gould M, Blanc P, et al. Asthma control, severity, and quality of life: quantifying the effect of uncontrolled disease. J Allergy Clin Immunol 2007; 120: 396-402.

43. Blozik E, Demmer I, Kochen MW, et al. Health-related quality of life in asthma patients from general practice. Dtsch Med Wochenschr 2009; 134: 873-8.

44. Hans-Wytrychowska A, Kurpas D, Sapilak BJ. The impact of socioeconomic status on the level of asthma control and the assessment of health-related quality of life (HRQoL) - own research [Polish]. Fam Med Prim Care Rev 2010; 12: 202-6.

45. Yen IH, Yelin EH, Katz P, et al. Perceived neighborhood problems and quality of life, physical functioning, and depressive symptomps among adults with asthma. Am J Public Health 2006; 96: 873-8.

46. Archea $\mathrm{C}$, Yen IH, Chen $\mathrm{H}$, et al. Negative life events and quality of life in adults with asthma. Thorax 2007; 62: 139-46.

47. Bandiera FC, Pereira DB, Ahmed AA, et al. Race/ethnicity, income, chronic asthma, and mental health: a cross-sectional study using the behavioral risk factor surveillance system. Psychosom Med 2008; 70: 77-84.

48. Wisnivesky JP, Leventhal H, Halm EA. Predictors of asthmarelated health care utilization and quality of life among innercity patients with asthma. J Allergy Clin Immunol 2005; 116: 636-42. 